Stream: Inspiring Critical Thought

News Update

(C) The Author(s), 2017

http://journals.sfu.ca/stream

\title{
PhD Defense
}

\section{Inventing Havana in Thin Air: Sound, Space, and the Making of Sonic Citizenship by Vincent Andrisani}

\author{
This is a news update from School of Communication, Simon Fraser University \\ News Editor: Christine Ackerley \\ Our dear colleague, Vincent Andrisani, will defend his PHD dissertation on Wednesday, July 12, \\ 2017 at Harbour Centre, Room 1520 (10:30-13:30). Here is the abstract of his dissertation \\ "Inventing Havana in Thin Air: Sound, Space, and the Making of Sonic Citizenship."
}

\begin{abstract}
The dissolution of the Soviet bloc (1989-1991) gave way to an acute economic crisis in Cuba known as the "Special Period in a Time of Peace". In Havana, the island's largest and most populated city, this historical moment consisted of widespread material scarcity, the dramatic increase of inequality, a housing crisis, and the re-emergence of the city's once-famed tourist geographies-all of which compelled residents to engage what is known as la lucha: the struggle to make ends meet. Although the worst of the crisis is now over, many of Havana's tenuous social, economic, and material conditions remain. This has prompted some to argue that the relationship between residents and the urban geography is conditioned by a logic of exclusion, and that the geo-social bond central to any notion of citizenship is fractured (Coyula, 2011; Ponte, 2002; 2011; Porter, 2008; Redruello, 2011). Yet, scholars have also observed residents spontaneously negotiating the precarity of everyday life, manifest in ingenuity with material objects, collective musical practices, or in individual maneuverings such as prostitution or street hustling (Del Real \& Pertierra, 2008; Fernandes, 2011; Carter, 2008).
\end{abstract}

This dissertation argues that residents also negotiate the precarity of Havana's urban geography using tacit, embodied practices made tangible through sound and listening. It asks, what are some of the everyday sounds that comprise the city's acoustic environments? How do such sounds accommodate or resist prevailing power structures? And to what extent can sound and listening mobilize a democratic spatial and political presence? Drawing from several months of ethnographic fieldwork, I argue that in the neighbourhood context, residents generate place-based social formations known as "acoustic communities" (Truax, 2001) that stand in contradistinction to the exclusionary logic of everyday life in the city. Borrowing from existing research in urban theory (Sassen, 2008; Holston, 1998; Cadava \& Levy, 2003; Isin, 2000), I conceive of these social formations using the term sonic citizenship, which I define as the communal production of acoustic spaces by those without sustained access to political power. During moments when sonic citizenship is enacted, we hear not only the political agency of Havana's residents, but also, the possibilities for the design of a future, more egalitarian city.

Keywords: sound; listening; space; everyday; community; citizenship 